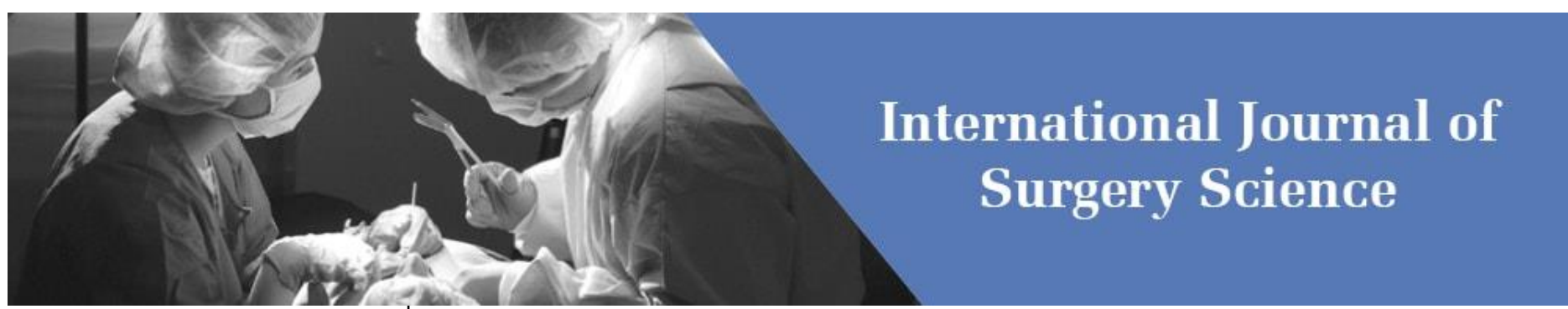

E-ISSN: 2616-3470

P-ISSN: 2616-3462

(C) Surgery Science

www.surgeryscience.com

2021; 5(4): 212-215

Received: 10-08-2021

Accepted: 12-09-2021

Dr. Rajnikant K Sanghvi

Assistant Professor, Department of Surgery, American International Institute of Medical Sciences, Kothibagh, Udaipur, Rajasthan, India
Corresponding Author: Dr. Rajnikant K Sanghvi Assistant Professor, Department of Surgery, American International Institute of Medical Sciences, Kothibagh, Udaipur, Rajasthan, India

\section{Comparative analysis of open versus laparoscopic cholecystectomy: A comparative study}

\section{Dr. Rajnikant K Sanghvi}

DOI: https://doi.org/10.33545/surgery.2021.v5.i4d.785

\section{Abstract}

Background and Aim: Gallstone disease (GSD or Cholelithiasis) is a significant health problem both worlds over (in both developing and developed nations). Earlier open cholecystectomy was the gold standard for treatment of stones in the gall bladder. The classical open cholecystectomy (OC) and the minimally invasive laparoscopic cholecystectomy (LC) are two alternative operations for removal of the gallbladder. The aim of the present study is to analyze the comparing Laparoscopic cholecystectomy and open cholecystectomy for cholecystitis.

Material and Methods: The present study was a comparative prospective randomized study done in a period of one year in the department of general surgery at tertiary care Institute of India. The study pool comprised of 140 subjects, divided in two groups of 70 subjects each. The division was done on the basis of the procedure to be employed for cholecystectomy viz LC or OC. Pain was measured using a visual analog scale (VAS). Blood loss was calculated using by gravimetric method by swab weighing.

Results: There were statistically significant differences among the average age between males and females of the study population. There was no statistical difference in the chief complaints between the two groups. In terms of operative characteristics, it was evident that the blood loss was statistically higher in open cholecystectomy cases. The commonest post-operative complication observed was nausea and vomiting, followed by abdominal distension, jaundice, wound infection and bleeding. The complications were higher among the open cholecystectomy cases.

Conclusion: Laparoscopic cholecystectomy is a safe procedure in elderly patients, with no increased risk of complications compared with the open procedure. The recovery is faster and the hospitals stay, shorter. It is important the correctly assess the cardiovascular surgical risk, since this group of patients have lower vital reserve, being more sensitive to surgical trauma.

Keywords: cholelithiasis, laparoscopic cholecystectomy, open cholecystectomy, visual analog scale

\section{Introduction}

Benign diseases of the biliary tract are one of the most common surgical problems in the world. Gallstones specifically affects millions ${ }^{[1]}$. The term cholecystectomy denotes surgical removal of gall bladder. It is the most common major abdominal surgery performed in western countries, an important indication being recurrent biliary colic. Carl Langenbuch performed the first successful open cholecystectomy in 1882. Cholecystectomy can be performed by open and laparoscopic methods. In 1987 Philippe Mouret of france first introduced Laparoscopic cholecystectomy and which quickly revolutionised the treatment of gall stone ${ }^{[2]}$. During last several years laparoscopic cholecystectomy has emerged worldwide as a preferred treatment for patients with cholecystitis and cholelithiasis. Benefits of this approach includes reduced hospitalisation and associated cost, less pain, avoidance of larger incision with improved cosmetic outcome, earlier postoperative recovery and return to work.

Gallstone disease (GSD or Cholelithiasis) is a significant health problem both worlds over. Earlier open cholecystectomy was the gold standard for treatment of stones in the gall bladder. The classical open cholecystectomy (OC) and the minimally invasive laparoscopic cholecystectomy (LC) are two alternative operations for removal of the gallbladder.

Cholecystectomy is the process of surgical removal of the gallbladder indicated by reason of symptomatic gallstones and other gallbladder conditions. It was Carl Johann August Langenbuch who performed the first cholecystectomy procedure in 1882 on a 43 year old man who was diagnosed with gallstones since almost 16 years and established cholecystectomy as an accepted modality for management ${ }^{[3]}$. 
From then onwards, open cholecystectomy (OC) was considered as the best treatment modality along surgical lines for gall stones till the late 1980s, when a French researcher, Philip Mouret successfully performed the first laparoscopic cholecystectomy (LC) on an adult subject in $1987^{\text {[4] }}$. Presently, LC enjoys the status of being a safe, reliable and routine procedure, preferred by both surgeons and patients due to its minimal access technique which includes reduced postoperative pain, faster mobilization of the patient, reduced hospital stay and better cosmetic results as compared to the open technique, which have further increased its applications ${ }^{[5]}$.

The incidence of gallstones is known to increase with an increase in age and demographic studies have demonstrated that females are more likely to have gallstones compared to males. It is estimated that approximately $20 \%$ of women and $5 \%$ of men in the age bracket of 50 to 65 years have gallstones. Overall, $75 \%$ of gallstones are composed of cholesterol and the other $25 \%$ are pigmented. Despite the differences in composition of gallstones and the variance among genders, the clinical signs and symptoms of the disease manifest similarly ${ }^{[6]}$.

Although laparoscopic cholecystectomy has largely supplanted traditional methods of performing open cholecystectomy for most patients with chronic uncomplicated cholecystitis and cholelithiasis, the open approach continues to be safe and effective therapy for complicated gall stone disease. There are a number of clinical situations that, when present make the laparoscopic approach more difficult and should prompt consideration of open approach.

Despite its widely propagated advantages, the pitfalls of LC are also well known. The lack of three dimensional imaging can lead to a limited surgical view and a lower discrimination of organelles. It is an obvious contra indication for patients who cannot sustain or are permitted general anaesthesia. In patients with cardiac illnesses, the carbon dioxide insufflations can induce arrythmias. Also the poor structural visualization can lead to the increased risk of hemorrhage and bile duct damage or leakage. Coupled with the elevated cost of equipment, the use of laparoscopic procedures in poorer set ups is a troublesome task [7-9].

The aim of the present study is to analyze the comparing Laparoscopic cholecystectomy and open cholecystectomy for cholecystitis.

\section{Material and Methods}

The present study was a comparative prospective randomized study done in a period of one year in the department of general surgery at tertiary care Institute of India. Ethical approval was taken from the institutional ethical committee and written informed consent was taken from all the participants.

\section{Inclusion criteria}

- Patients more than 20 years with either gender

- With one or multiple gallstones diagnosed on ultrasonography.

\section{Exclusion criteria}

\section{- Patient's age below 20 years}

- History or investigations suggesting jaundice, gall bladder mass, mucocele, empyema, portal hypertension, cirrhosis of the liver, coagulopathy and pregnancy

The subjects were subjected to thorough history taking and general examination process. The routine investigations as well as radiology imaging were performed prior to the surgery. Other protocols were followed as per standardized regulations prevailing in the institution. The study pool comprised of 140 subjects, divided in two groups of 70 subjects each. The division was done on the basis of the procedure to be employed for cholecystectomy viz LC or OC. Pre-operative checkups and admissions were similar for both cases. The duration of surgery was noted as the time from initiation if skin incision, up to the time till final closure of sutures. Pain was measured using a visual analog scale (VAS). Blood loss was calculated using by gravimetric method by swab weighing. In LC it was measured by the volume of irrigation fluids and subtracted from volume from the fluid collected in suction bottles to estimate the final blood loss.

\section{Statistical analysis}

The recorded data was compiled and entered in a spreadsheet computer program (Microsoft Excel 2007) and then exported to data editor page of SPSS version 15 (SPSS Inc., Chicago, Illinois, USA). For all tests, confidence level and level of significance were set at $95 \%$ and $5 \%$ respectively.

\section{Results}

The study sample comprised of 140 adult subjects including 85 males and 55 females. (Table 1) The average age of the study subjects was $44.90 \pm 15.2$ years. There were statistically significant differences among the average age between males and females of the study population. The majority of the individuals $(n=102)$ were from a rural residential area, while the rest of the subjects $(n=38)$ were from urban area. (Table 2) The predominant occupation among the study subjects were agriculture and livestock related. Other professions included shopkeepers, mine workers and housewives or unemployed. The clinical presenting complaints of subjects were varied. Maximum had a chief presenting complaint of abdominal pain or discomfort, followed by nausea/vomiting, indigestion and dyspepsia. There was no statistical difference in the chief complaints between the two groups. In terms of operative characteristics, it was evident that the blood loss was statistically higher in open cholecystectomy cases. The same was seen in total duration of stay and average pain scores among the subjects.

The commonest post-operative complication observed was nausea and vomiting, followed by abdominal distension, jaundice, wound infection and bleeding. There was a statistically significant difference seen between both the groups in the study. The complications were higher among the open cholecystectomy cases. Financially, the cumulative average cost of OC was lower as compared to LC which was statistically significant. Patient response was variable as regards to the procedure. All patients were asked to submit a response on their operative and postoperative care and none of the subjects reported any adverse comments.

Table 1: Gender wise Distribution of Study Participants

\begin{tabular}{|c|c|c|}
\hline Gender & Number & Percentage \\
\hline Male & 85 & 60.7 \\
\hline Female & 55 & 39.28 \\
\hline Total & 140 & 100 \\
\hline
\end{tabular}

Table 2: Area Wise Distribution of Study Participants

\begin{tabular}{|c|c|c|}
\hline Area & Number & Percentage \\
\hline Rural & 102 & 72.85 \\
\hline Urban & 38 & 27.14 \\
\hline Total & 140 & 100 \\
\hline
\end{tabular}




\section{Discussion}

Cholelithiasis is one of the most important surgically correctable diseases. Though open cholecystectomy was the main stay of treatment in past, in recent time laparoscopic cholecystectomy has replace it widely. In several studies it has been seen that there are many advantages in laparoscopic cholecystectomy over open method such as reduced operative time, less intra and postoperative complications, less post-operative pain and a shorter hospital stay and for which now a day's many surgeons are adopting this procedure. Even patients are now more inclined to laparoscopic cholecystectomy due less pain, early mobilisation and better cosmetic result ${ }^{[10-12]}$

The present study was conducted with a study population of 140 subjects which were dominantly male. The disparity was due to the fact that in the study duration, the authors had a lower female turnout in outpatient wards. The mean age of the subjects was $44.90 \pm 15.2$ years. This is in concurrence to studies reported by Doke et al and Shukla et al wherein the authors had a similar age group in their study sample ${ }^{[13,14]}$.

The commonest presenting complaint was abdominal pain and discomfort in both the groups. There was no statistically significant difference in the chief presenting complaints in our study. This is similar to studies by various authors, wherein the commonest complaints are abdominal pain and distension ${ }^{[10-13]}$.

The mean duration of surgery in the LC group was 85.2 minutes as compared to a lower time for open surgery which held at 65.4 minutes by average. This difference was statistically significant. The study shows a lower time in OC cases and is similar to studies by Doke et al, Shukla et al and Chattopadhyay et al wherein the authors reported a lower duration of surgery thought the difference in duration was varied ${ }^{[13-15]}$ Most studies reported lesser pain in laparoscopic surgery as compared to open surgery. Many publications have reported that Laparoscopic cholecystectomy is associated with shorter hospital stay. ${ }^{16}$ Shorter hospital stay remains the main advantage of the laparoscopic cholecystectomy. Ogola $\mathrm{G}$ et al, also showed the same results ${ }^{[17]}$. Early return to normal as well as occupational activities is a key feature of laparoscopic surgery. Present studies were similar to studies conducted by Guan G, et al, who found that patients who underwent laparoscopic cholecystectomy could return to their routine faster when compared to the open procedure ${ }^{[18]}$.

The average blood loss in OC cases was higher, with 38 subjects reporting a loss of over $100 \mathrm{ml}$ blood compared to only 10 cases in LC group. This is in concurrence with studies by Shukla et al, Sheikh et al and Poggio et al. ${ }^{[14,19,20]}$

The pain in the post-operative period was lower in LC groups as compared to the OC group, owing to the fact that being a minimally invasive procedure, the likelihood of tissue damage is less. This in turn leads to lower pain score and reduces usage of analgesics as well as hastens recovery time. These parameters are consistent with studies by Doke et al, Shukla et al, Chattopadhyay and Karim et al who reported that the mean pain score, recovery time and time for resumption of normal activities was lower in case of LC as compared to traditional method $[9,13,15,21]$

The number of subjects with postoperative complications was higher in OC group in the present study. The commonest complication was nausea and vomiting, followed by distension and jaundice. The limiting factor was the fact that only OC group had features or complaints of wound infection.

Similar to our study several authors such as Karim T et al, Ajay Gangji et al, and Lujan JA et al showed a higher rate of complication in open cholecystectomy group compared to laparoscopic group [21, 22] Though Lujan et found that the association of lesser complications in laparoscopic cholecystectomy group was not statistically significant $(\mathrm{p}=0.001)$ there are many other authors such as Doke A et al and Medeiros AC et al found a statistically significant. Lower rate of complications in laparoscopic group compared to that in open group ${ }^{[22]}$ Doke A et al showed in their study $28 \%$ complication in Open group compared to $16 \%$ in laparoscopic Cholecystectomy while Medeiros AC et al found $2.9 \%$ complication in laparoscopy group and $5.13 \%$ in open group.

\section{Conclusion}

Laparoscopic cholecystectomy is a safe procedure in elderly patients, with no increased risk of complications compared with the open procedure. The recovery is faster and the hospital stay, shorter. It is important the correctly assess the cardiovascular surgical risk, since this group of patients have lower vital reserve, being more sensitive to surgical trauma.

However, its necessity does arise in cases where access to minimally invasive surgery is hampered owing to infrastructural and skill availability issues. In rural India, access of high end healthcare is limited and if available is expensive. Here the OC does play a role in imparting a substitute.

\section{References}

1. Russell RCG, Williams NS, Bulstrode CJK. Bailey and Love short practice of surgery. 24th edn. London: Hodder Arnold 2004.

2. Oddsdottir M, Pharm TH. Gall bladder and the extra hepatic biliary system. In: Brunicardi FC, Andersen DK eds. Schwartz's principles of surgery. 9th edn. USA: McGrawHill Professional 2009, 1151-1152.

3. De U. Evolution of cholecystectomy: a tribute to Carl August Langenbuch. Indian J Surg 2004;66(2):97-100.

4. Mouret P. Celioscopic surgery. Evolution or revolution. Chirurgie 1990;116(10):829-33.

5. Wang Y, Wang YT, Jiang YY, Lin YH, Zou ZD. Effect of different position and $\mathrm{CO}$ (2) pneumoperitoneum on deep vein hemodynamics of lower limb. Zhonghua Wei Chang Wai Ke Za Zhi 2009;12(4):361-3.

6. Kose SH, Grice K, Orsi WD, Ballal M, Coolen MJ. Metagenomics of pigmented and cholesterol gallstones: the putative role of bacteria. Sci Rep 2018;8(1):1-3.

7. Choy I, Kitto S, Aryee N, Okrainec A. Barriers to the uptake of laparoscopic surgery in a lowermiddle- income country. Surg Endosc. 2013;27(11):4009-15.

8. Lundberg O, Kristoffersson A. Open versus laparoscopic cholecystectomy for gallbladder carcinoma. J Hepatobiliary Pancreat Surg 2001;8(6):525-9.

9. Pessaux P, Regenet N, Tuech JJ, Rouge C, Bergamaschi R, Arnaud JP. Laparoscopic versus open cholecystectomy: a prospective comparative study in the elderly with acute cholecystitis. Surg Laparosc Endosc Percutan Tech 2001;11(4):252-5.

10. Goco IR, Chambers LG. Dollar and cents: minicholecystectomy and early discharge. South Med J 1988;81(2):161-163.

11. Rajabi-Mashhadi MT, Abdollahi A, Tavassoli A, et al. Laparoscopic cholecystectomy: a retrospective fouryear study. J Minim Invasive Surg Sci 2015;4(2):e25253.

12. Shukla A, Seth S, Ranjan A. A comparative study between laparoscopic and open cholecystectomy in cases of cholecystitis with cholelithiasis: one year experience in tertiary care center. Int Surg J 2017;4(3):903-907. 
13. Doke A, Gadekar N, Gadekar J, Dash N, Unawane S. A comparative study between open versus laparoscopic cholecystectomy. Sch J App Med Sci. 2016;4(1):57-61.

14. Shukla A, Seth S, Ranjan A. A comparative study between laparoscopic and open cholecystectomy in cases of cholecystitis with cholelithiasis: one year experience in tertiary care center. Int Surg J 2017;4(3):903-7.

15. Chattopadhyay K, Das R. Laparoscopic and open cholecystectomy: a comparative study. International J Surg Sci. 2020;4(1):427-30.

16. Ansaloni L, Pisano M, Coccolini F, Peitzmann A, Fingerhut A, Catena $\mathrm{F}$ et al. WSES guidelines on acute calculous cholecystitis. World J Emerg Surg 2016;11(1):25.

17. Ogola G, Crandall M, Shafi S. Variations in outcomes of emergency general surgery patients across hospitals: a call to establish emergency general surgery quality improvement program. J Trauma Acute Care Surg 2018;84(2):280-6.

18. Guan G, Sun C, Ren Y, Zhao Z, Ning S. Comparing a singlestaged laparoscopic cholecystectomy with common bile duct exploration versus a two-staged endoscopic sphincterotomy followed by laparoscopic cholecystectomy. Surgery 2018;164(5):1030-4.

19. Sheikh U, Azam S, Mallah MQ, Laghari QA, Choudhry AM. Comparative study of morbidity of laparoscopic versus open cholecystectomy in complicated gallstone disease. GOMAL J Med Sci 2011;9(2):200-3.

20. Poggio JL, Rowland CM, Gores GJ, Nagorney DM, Donohue JH. A comparison of laparoscopic and open cholecystectomy in patients with compensated cirrhosis and symptomatic gallstone disease. Surgery 2000;127(4):40511 .

21. Karim T, Kadyal A. A comparative study of laparoscopic vs. open cholecystectomy in a suburban teaching hospital. J Gastrointest Dig Syst 2015;5:371.

22. Anmol N, Lakshminarayan G, Manohar TM, Avadhani GK, Abinash H. Outcome following open and laparoscopic cholecystectomy. J Evolution Med Dental Sci 2014;3(15):4061-71. 